Mini Review

\section{Three visionaries for HRT}

\section{Joseph Loze Onwude*}

Independent Gynaecologist, Rochester House Clinic, Great Leighs, Chelmsford CM3 1ND, UK

\section{Introduction}

When a woman consults a doctor about Hormone Replacement Therapy (HRT), the first concern is that there is an increased risk of breast cancer with HRT. And this sole reason might be the reason for refusing the offer of HRT. However, this practice has minimal basis and evidence to support it. Although HRT is an umbrella term, women who have no uterus receive oestrogen-only HRT or Estrogen Replacement therapy (ERT). No valid study has linked ERT with an increased risk of breast cancer [1,2]. The only other study that came close to describing the relationship between ERT and Breast Cancer is the collaborative study [3]. However this re-analysis was grossly deficient because it performed a meta-analysis on studies that were not all randomised controlled trials which naturally remove the bias, known or unknown confounders of just cohort prospective studies and analysed then as nested case control studies - a retrospective analysis. Shapiro, et al, adequately describe the deficiencies of the collaborative study with regards to causal relationship between HRT and Breast cancer, and much less between ERT and breast cancer [4]. We confirmed the thoughts of Shapiro, et al. in 2019 [5].

This women described by the visionaries did not differentiate between women who were receiving HRT because they still had a uterus or women who had no uterus because of previous hysterectomy alone or women who have had the removal of their ovaries at the time of hysterectomy, from any age. The evidence, including long term follow-up has clarified the picture of the limitations of HRT or ERT.

When HRT is required because a woman still has a uterus, then the risk is consistently higher for the development of breast cancer. However, this risk is only higher, on the basis of evidence, for women who receive Progesterone as tablets for endometrial protection against irregular uterine bleeding, hyperplasia of endometrial lining or the rare risk of endometrial cancer [6]. When the progestogen is supplied as an intrauterine source, this risk of breast cancer is not increased. This supports that oral Progesterone is the plausible causative agent in the increased risk of breast cancer from HRT. Can we deliver HRT without oral progesterone? Yes, we can.

\section{More Information}

*Address for Correspondence: Joseph Loze Onwude, The Croft, Warley Road, Great Warley, Brentwood CM13 3HT, UK, Email: jlonwude@btconnect.com

Submitted: December 07, 2020

Approved: January 14, 2021

Published: January 15, 2021

How to cite this article: Onwude JL. Three visionaries for HRT. Clin J Obstet Gynecol. 2021; 4: 007-009.

\section{DOI: 10.29328/journal.cjog.1001077}

Copyright: (c) 2021 Onwude JL. This is an open access article distributed under the Creative Commons Attribution License, which permits unrestricted use, distribution, and reproduction in any medium, provided the original work is properly cited.

Check for updates

O open access

\section{The visionaries for HRT}

More than fifty years ago, Robert A Wilson, an English Gynaecologist living in New York published 'Feminine Forever' [7], which was credited with raising the profile and sales of Hormone Replacement Therapy (HRT) in the United States. HRT was presented as a therapy that allowed women to free themselves from the malediction of Estrogen loss, and to conserve femininity. It is alleged that his name fell into disrepute because he failed to disclose that the publication of 'Feminine Forever' was underwritten by a pharmaceutical company, Ayerst.

Nevertheless, the works of Dr. Wilson were visionary. Dr. Wilson firmly believed and promoted that menopause was a state of Estrogen deficiency, and like diabetes, thyroid and adrenal deficiencies, Estrogens should be replaced in menopausal women. He advocated that menopause was not a natural state to be accepted as part of ageing but as a situation that should be treated with Estrogen replacement. In addition, he went as far as to advocate that menopause should be prevented with Estrogen use during the peri-menopausal years and menopausal years! This declaration has still not been realised because of concerns about the long-term risks of Estrogen therapy.

Robert Wilson shocked audiences by pronouncing that menopause was equivalent to castration, be it natural or radiation, medical or surgical menopause. This still sounds drastic today, but the concept that menopause is equivalent to the castration of women has a reality for women. 
Feminine Forever' was published just before the decade when concerns about uterine cancer were associated with unopposed Estrogen-only HRT. The resolution of this risk was by additional Progestogens. This risk did not dampen the enthusiasm for Estrogen as a treatment for menopausal symptoms.

Women who have read 'Feminine Forever' consider that Robert Wilson was way ahead of his time because the issues that he raised before 1966, particularly about the perimenopausal woman who can be radically different and more affected than the menopausal woman, are still prevalent and relevant today. He clearly described the peri-menopausal woman and the pressures that these women face. For example, he identified that such a woman might be competing in industry with men, caring for adolescent children and/or elderly or sick parents and sometimes, her husband's parents at a critical time in their lives when their female hormones, particularly Estrogens were fluctuating and therefore debilitating.

According to Robert Wilson 'Estrogen itself acts as a natural energizer to both mind and body. Women rich in Estrogen tend to have a certain mental vigour that gives them selfconfidence, a sense of mastery over their destiny, the ability to think out problems effectively, resistance to mental and physical fatigue and emotional self-control. Their emotional reactions are proportional to the occasion. They neither overreact hysterically nor do they tend towards apathy. They are, as a rule, capable of facing the whole world with a healthful relaxed attitude and thereby able to enjoy their daily life. They are seldom depressed. Irrational crying spells are virtually unknown among them.

He continues that 'in a family situation, Estrogen makes women adaptable, even-tempered, and generally easy to live with. Consequently, a woman's Estrogen carries significance beyond her own well-being. It also contributes toward the happiness of her family and all those with who she is in daily contact'.

The book ends with a legacy that women should not just go into the $21^{\text {st }}$ century with knowledge that they can remain 'Feminine Forever' but that they should consider 'Femininity' as an essential component of their lives. These visions were restricted, until recently, by concerns about Estrogen-only HRT, uterine cancer, HRT and incidence of breast cancer and the incidence of thrombosis. These visions are easier to realise now that we clearly know that long-term Estrogenonly HRT does not increase the risk of breast cancer and more likely to protect against breast cancer, that uterine cancer can be prevented by additional progestogens and that risks of thrombotic complications like deep vein thrombosis, pulmonary embolism and thrombotic strokes are only associated with oral Estrogen-in ERT or oral Estrogen-in HRT.

Wendy Cooper, an English journalist was another visionary for HRT. More than forty years ago, she published 'No Change' [8], when most of the current senior English doctors would have been in medical training, in an environment where Estrogen of HRT was strongly considered to cause breast cancer and venous thrombosis and when HRT caused breakthrough uterine bleeding that required investigations to exclude uterine cancer. 'No Change' could be credited with raising the profile of HRT among doctors and the public in the UK. She admits to using HRT herself with beneficial results.

She tackled the controversies in Medicine, about what doctors believed then about breast cancer, thrombosis, breakthrough bleeding and what doctors still worry about now.

In 'No Change', Wendy Cooper was visionary in her interpretation of the evidence that did not support the worries of doctors at the time. She did not believe that the evidence at the time supported that Estrogen only HRT caused breast cancer or that Estrogen only HRT increased the risk of venous thrombosis. These interpretations have been confirmed by recent properly acclaimed long term reports of randomised controlled studies [2].

Wendy Cooper emphasises a phrase that epidemiologists now repeatedly espouse to modern doctors, that "association" is not "cause". This means that an association, no matter how strong, between an exposure like HRT and breast cancer does not even remotely mean that 'HRT causes breast cancer', especially in observational studies. Hopefully, the significance of this well known fact will be expressed by modern doctors during counselling, as Wendy Cooper espoused.

The third visionary for HRT was Teresa Gorman, an English teacher, scientist, business woman and a member of United Kingdom Parliament. In 2003, she published 'Hooray for HRT' [9], which can be credited for raising the profile of HRT in the British House of Commons and the public. In her 40's, she began to experience the debilitating effects of the menopause. She found relief with HRT. This prompted her to set up the Amarant Trust to inform other women, the public and the British Government, about older women and the problems of menopause. She strongly promoted that the benefits of HRT far outweighed the risks. The evidence from long-term followup of women in the randomised Women Health Initiative studies [2] completely agrees with her interpretation of the research results at the time, which showed no increase on all cause mortality from HRT or ERT, and that the latter might be protective against breast cancer.

This book strongly advocated that the benefits of HRT in the long-term for women were grossly underplayed, because of unjustified risks. She pointed her finger at some cancer charities and academic establishments that continued to produce inappropriate studies on "cause and effect" relationship between HRT and Breast cancer. She emphasised that these charities got publicity that could only harm women in the longer term. She strongly pointed out that breast 
cancer charities have continued to promote the notion that HRT caused breast cancer to swell their coffers, when the evidence was different. For example, that the evidence has been consistent that Estrogen-only HRT did not increase the risk of breast cancer [2]. Secondly, that with the combinedHRT, the evidence had not consistently showed the cause and effect relationship. We now know that she is correct about Estrogen-only HRT which at worst is that Estrogen-only HRT does not increase the risk of breast cancer and at best that this type of HRT significantly protects against breast cancer. The cause and effect relationship has been established if women with a womb uses oral progestogens for at least 5 years. If alternatives that deliver Progestogens to the uterus only, like the Mirena coil, are used, the risk of breast cancer related to HRT becomes negligible. But you must remember that Mrs Gorman was a scientist.

Mrs. Gorman was bold in advocating that 'age and ageing' is irrelevant to a woman on HRT. Her picture on the cover of 'Hooray for HRT' shows a 79 year old without any wrinkles and with all her faculties. One can only extrapolate that she benefitted from the long-term benefits of HRT, having started HRT in her 40's. She died naturally at the age of 85 years.

This visionary also advocated a little known fact, even in today's medicine, that Estrogen allows the body to renew itself. There is copious evidence that Estrogens promote cell proliferation, differentiation, and development in many tissues, as well as on metabolism, immunity, and cognition.

Each of these visionaries have contributed to the debate in different ways:

\section{Benefits}

Teresa Gorman believed in the benefits, and damned the consequences. She was right!

\section{Risks}

Wendy Cooper simply explained that the incidence of breast cancer in women is not higher when the levels of estrogens are persistently high in women, for example during repeated pregnancies and before the peri-menopause.

She correctly interpreted evidence that shows what the current evidence shows that Estrogen only HRT prevents against breast cancer. In addition, the risk of thrombotic events are unchanged provided oral estrogen tablets are avoided, She was right.

\section{Prevention}

Most carers and their women can accept that Estrogen alone HRT and combined HRT can be useful for women with disturbing menopausal symptoms. This is now more acceptable because the risks are clearer for Estrogen alone HRT - reduced risk of breast cancer and no added risk of thrombosis provided tablet Estrogens are avoided. For combined HRT, provided oral Estrogens are not used, the risk of thrombosis is not increased. Similarly provided oral Progestogens are not used, the risk of breast cancer should not be increased.

As far as Robert Wilson was concerned in 1966, the most important vision for HRT in the $21^{\text {st }}$ Century was in its preventive role. This logical quest stalled for 50 years because of arguments over the risks of Estrogen.

Can doctors and their women look forward to a realistic prevention of breast cancer, cardiac disease, osteoporosis, Alzheimer's disease, skin wrinkles, poorer vision and memory, muscle and cartilage problems like severe low back pain, migraines or depression without fear of harm to themselves?

If this is so, the important visions of Teresa Gorman, Wendy Cooper and Robert Wilson will have come true.

When you combine the visions of these three people with current long-term evidence, you get a coherent message to peri-menopausal and menopausal women to prevent and treat the menopause, that short and long-term benefits outweigh minimal risks.

The only aspect that was not so clear cut was that oral estrogen and oral progesterone in HRT carried the risks. The deeper we look into this, the clearer that the three visionaries were right.

\section{References}

1. Anderson GL, Chlebowski RT, Aragaki AK, Kuller LH, Manson JE, et al. Conjugated equine oestrogen and breast cancer incidence and mortality in postmenopausal women with hysterectomy: extended follow-up of the Women's Health Initiative randomised placebocontrolled trial. Lancet Oncology. 2012; 13: 476-486.

PubMed: https://pubmed.ncbi.nlm.nih.gov/22401913/

2. Chlebowski RT, Garnet L, Anderson GL, et al. Long-term influence of estrogen plus progestin and estrogen alone use on Breast cancer incidence: The Women's Health Initiative Randomised Trials. San Antonio Breast Cancer Symposium. 2019.

3. Collaborative Group on Hormonal Factors in Breast Cancer. Breast cancer and hormone replacement therapy: collaborative reanalysis of data from 51 epidemiological studies of 52,705 women with breast cancer and 108,411 women without breast cancer. Lancet. 1997; 350: 1047-1059. PubMed: https://pubmed.ncbi.nlm.nih.gov/10213546/

4. Shapiro S, Farmer RDT, Seaman H, Stevenson JC, Mueck AO. Does hormone replacement therapy cause breast cancer? An application of causal principles to three studies Part 1. The Collaborative Reanalysis. J Fam Plann Reprod Health Care. 2011; 37: 103-109. PubMed: https://pubmed.ncbi.nlm.nih.gov/21454266/

5. Manyonda I, Onwude JL. Rapid response to: Use of hormone replacement therapy and risk of breast cancer: nested case-control studies using the QResearch and CPRD databases. BMJ. 2020; 371.

6. Manyonda I, Talaulikar VS, Pirhadi R, Onwude J. Progestogens are the problem in hormone replacement therapy: Time to reappraise their use. 2019.

7. Robert Wilson. Feminine Forever. Publisher: WH Allen Publishing USA. 1966.

8. Cooper W. No Change. Hutchinson Publishing, 1975.

9. Gorman T. Hooray to HRT. 2013 